\title{
DEFICIÊNCIA INTELECTUAL EM PERSPECTIVA: CONCEPÇÕES E EVOLUÇÃO CONCEITUAL
}

\author{
INTELLECTUAL DISABILITY IN PERSPECTIVE: CONCEPTIONS \\ AND CONCEPTUAL EVOLUTION
}

\begin{abstract}
DEFICIENCIA INTELECTUAL EN PERSPECTIVA: CONCEPCIONES Y EVOLUCIÓN CONCEPTUAL
\end{abstract}

\author{
Andressa Caetano Mafezoni ${ }^{\mathrm{I}}$ \\ ThaYNÁ MARINS DE Almeida CÉSAR ${ }^{\text {II }}$ \\ DAMARIS SANTOS DE SouzA ${ }^{\text {III }}$
}

IUniversidade Federal do Espírito Santo (UFES), Vitória/ES-Brasil "Universidade Federal do Espírito Santo (UFES), Vitória/ES-Brasil 'Universidade Federal do Espírito Santo (UFES), Vitória/ES-Brasil

\begin{abstract}
RESUMo Objetiva-se apresentar, pela via da literatura acadêmica, as concepções de professores acerca da deficiência intelectual, assim como as modificações desse conceito ao longo do tempo pela Associação Americana de Deficiência Intelectual e Desenvolvimento (AADID), por meio de uma pesquisa de natureza qualitativa de cunho bibliográfico. Como discussões e considerações, constatou-se que os trabalhos analisados na literatura mostram que os professores concebem a deficiência intelectual numa perspectiva de limitação de ordem biológica em relação às possibilidades de desenvolvimento e aprendizagem dos alunos e que as modificações do conceito de deficiência intelectual ao longo do tempo não deixaram para trás a perspectiva biológica, o que continua por caracterizar os indivíduos que vivem nessa condição como delimitados pela não aprendizagem.
\end{abstract}

Palavras-Chave: Deficiência intelectual; Professores; Aprendizagem.

Abstract The objective of this paper is to present, through the academic literature, the teacher's conceptions about intellectual disability, as well as the modifications of this concept over time by the American Association of Intellectual Disability and Development (AAIDD), through a qualitative research of bibliographic character. As discussions and considerations, it was found that the papers analyzed in the literature show that teachers conceive the intellectual disability in a perspective of biological limitation in relation to 
the possibilities of students development and learning and that changes in the concept of intellectual disability over time have not left behind the biological perspective, which still characterizes individuals living in this condition as delimited by non-learning.

KeyWORDS: INTELLECTUAL DEFICIENCY; TeACHERS; LeARNING.

Resumen El objetivo de este trabajo es presentar, a través de la literatura académica, las concepciones de los maestros sobre la deficiencia intelectual, así como las modificaciones de este concepto a lo largo del tiempo por parte de la Asociación Americana de Discapacidad Intelectual y Desarrollo (AADID), a través de una investigación cualitativa de carácter bibliográfico. Como discusiones y consideraciones, se encontró que los artículos analizados en la literatura muestran que los docentes conciben la discapacidad intelectual en una perspectiva de limitación biológica en relación con las posibilidades de desarrollo y aprendizaje de los estudiantes y que los cambios en el concepto de discapacidad intelectual a lo largo del tiempo no han dejado atrás la perspectiva biológica, que aún caracteriza a los individuos que viven en esta condición como delimitados por el no aprendizaje.

Palabras Clave: Discapacidad intelectual; Maestros, Aprendizaje.

\section{INTRODUÇÃo}

No decorrer da história, a deficiência tem sido marcada pela exclusão daqueles que não correspondem ao padrão físico e/ou intelectual em relação aos demais indivíduos nos contextos sociais. $\mathrm{O}$ indivíduo que está fora desse padrão tem sido impedido muitas vezes de compartilhar com os demais os bens socioculturais construídos pela humanidade. Lidar de forma normalizada com esses sujeitos subentende enxergá-los somente como um corpo orgânico, visto em desvantagem se comparado ao corpo padrão/normal, que, por sua vez, é entendido como ágil e produtivo. Essa dicotomia limita a construção de vínculos sociais, afetivos, empregatícios e os demais, considerados importantes para a vida em sociedade.

Dessa maneira, dependendo do olhar e do meio social no qual a pessoa com deficiência está inserida, a sua convivência na coletividade pode tornar-se mais restrita ou não, de acordo com as atitudes ancoradas em modelos que são preestabelecidos como padrões sociais. Levando em consideração que a escola faz parte dessa convivência coletiva em nossa sociedade, é necessário refletir sobre seu papel transformador, na medida em que acolhe a diversidade e a diferença, conjugadas com outros direitos sociais e políticas públicas, como o direito à educação e à educação inclusiva, com o objetivo de promover o processo de aprendizagem e o desenvolvimento de todos os alunos.

Nesse sentido, de modo geral, quando pensamos em aprendizagem, automaticamente estabelecemos relação com a escola e os conteúdos decorrentes do currículo escolar, que são elementos característicos das instituições educacionais. O processo de aprendizagem torna-se imprescindível para que os alunos aprendam e por conseguinte signifiquem as trocas sociais entre as pessoas. Assim, compreendemos a escola como um elemento importante para a aprendizagem e o desenvolvimento dos alunos, entendendo-a como instância potencializadora do processo de inclusão escolar de crianças com ou sem deficiência, comprometida com cada aluno em parceria com os demais atores sociais. 
Nessa perspectiva, a educação inclusiva como uma política pública, realizada por meio da inclusão escolar, foi impulsionada no Brasil ao final da década de 1980, em meio às discussões sobre os direitos humanos em educação e documentos internacionais que refletiram um movimento pró-educação inclusiva. Nesse sentido, o país tornou-se signatário dessas orientações, modificando a estrutura das políticas educacionais por intermédio da Lei de Diretrizes e Bases da Educação Nacional nº. 9394, de 20 de dezembro de 1996; da Política Nacional de Educação Especial na Perspectiva da Educação Inclusiva, de 2008, e mais recentemente por meio da promulgação da Lei Brasileira de Inclusão (LBI) da Pessoa com Deficiência (Estatuto da Pessoa com Deficiência) n n. 13.146, de 6 de julho de 2015, entre outras orientações e documentos.

Essas políticas públicas vêm reforçando a necessidade de que a União, os Estados, os municípios e a sociedade busquem possibilidades para a realização de ações que promovam a inclusão escolar numa perspectiva que é mundial, com ênfase na educação em direitos humanos. Nesse ínterim, a educação inclusiva, como uma forma de promover a aprendizagem para todos os alunos, é uma discussão importante e necessária, pois o movimento de convivência com a diferença promove articulações entre as pessoas, possibilitando o entendimento da realidade, o que pode modificar os olhares e as ações coletivas que possibilitem a equidade humana.

A esse respeito, é necessário pontuarmos as discussões sobre a conceituação da deficiência e, especificamente neste artigo, a respeito da deficiência intelectual. ${ }^{1}$ Assim como Dias (2017, p. 25), entendemos ser uma construção abstrata e social, cuja caracterização depende de como é definida, isto é, com qual perspectiva e finalidade é elaborada. Na escola brasileira, o conceito de deficiência intelectual ainda tem as marcas de uma educação especial ancorada em um modelo médico-psicológico e por conseguinte também em suas práticas pedagógicas. Esse conceito permeia o meio educacional brasileiro desde quando os responsáveis em gerir a instrução pública, no início do século XX, aderiram ao uso de instrumentos de medida da inteligência para separar as crianças "normais" das "anormais" e as "aptas" das "inaptas", dando seguimento às teorias francesas.

Para além das marcas das teorias francesas sobre a deficiência intelectual nas políticas públicas brasileiras, também sofremos influência de outras instituições, como a Associação Americana de Deficiência Intelectual e Desenvolvimento (AADID), localizada em Washington, nos Estados Unidos, fundada em 1876, cujo primeiro manual foi escrito em 1921. É reconhecida internacionalmente por ser o órgão mais antigo na linha de pesquisa sobre deficiência intelectual, estabelecendo conceituações, classificações, modelos teóricos e orientações de intervenções em diferentes áreas. Dessa maneira, o objetivo deste texto é apresentar, pela via da literatura acadêmica, as concepções de professores acerca da deficiência intelectual, assim como as modificações desse conceito ao longo do tempo pela Associação Americana de Deficiência Intelectual e Desenvolvimento (AADID).

Este texto faz parte de um projeto maior de pesquisa que tem por objetivo aprofundar as discussões acerca do conceito de deficiência intelectual, a partir do conceito de inteligência. Para este momento da pesquisa, apresentamos, como movimento metodológico, os

" Neste texto, utilizaremos os termos "retardo mental", "deficiência mental" e "deficiência intelectual" de acordo com o período histórico. 
pressupostos da pesquisa qualitativa do tipo bibliográfico, conforme discutido por Lima e Mioto (2007) e Andrade (2010).

Para eleger o material de leitura, utilizamos a base de dados Scientific Eletronic Library (SciELO), dissertações e teses de bibliotecas digitais de universidades brasileiras, assim como outros materiais, inclusive livros impressos e políticas/legislação obtidas de modo eletrônico. Foram utilizados os descritores AAMR, AADID, classificação da deficiência mental, classificação da deficiência intelectual, concepções de professores sobre a deficiência intelectual.

Após a seleção do material, realizamos a leitura dos resumos de artigos, dissertações e teses, com a predefinição de que fizessem menção às concepções de professores acerca da deficiência intelectual e à construção do conceito de deficiência intelectual, de forma interdependente ou não. De igual modo, para realizar o recorte temporal, levamos em consideração as discussões sobre a temática, a partir da década de 1990, quando, com o advento da inclusão escolar de estudantes com deficiência no ensino comum, houve um aumento da publicação de trabalhos científicos a respeito do tema.

Em relação à leitura e análise qualitativa do material selecionado, organizamos o texto em três momentos: no primeiro, fundamentamos o estudo situando a educação especial e o conceito de deficiência intelectual, com contribuições de estudiosos da área; no segundo, apresentamos o conceito de deficiência intelectual e a escola e, por fim, elencamos algumas definições da AADID sobre a deficiência intelectual, a partir das quais os achados foram estudados à luz da literatura científica contemporânea envolvendo a temática.

\section{SituANDo A EDUCAÇÃo ESPECIAL E O CONCEITO DE DEFICIÊNCIA INTELEC- TUAL}

Neste momento do texto, apontamos as contribuições de estudiosos da área da educação especial que oferecem argumentação condizente à discussão ora apresentada, dado que o debate acerca do conceito de deficiência intelectual ainda é permeado por contradições e, por isso, é importante discutir e compreender as origens e os significados que o conceito vem adquirindo ao longo do tempo. Nessa perspectiva, compreende-se que a educação especial brasileira ainda carece de acompanhar os passos das mudanças socioeducacionais e seu desenvolvimento na atualidade, por não romper com o modelo médico-psicológico e a classificação de sujeitos por meio do Quociente de Inteligência (QI). A retomada dessa discussão se faz necessária, levando-se em consideração que, em tempos de inclusão escolar, ainda temos visto práticas pedagógicas que concebem a deficiência intelectual como algo individual e "a-social", pelo fato de que o conceito de deficiência foi construído na trajetória histórica de formações sociais estabelecidas que foram exigindo gradativamente determinadas formas de produtividade intelectual, as quais culminariam na caracterização de um tipo de indivíduo - os deficientes mentais (BUENO, 2009).

A literatura aponta que a educação especial, no Brasil, se constituiu a partir de bases médico-psicológicas-pedagógicas (BATISTA, 2009; BRIDI, 2011; GUARIDO, 2008; JANNUZZI, 2006; SILVA, 2016). Mais especificamente, na segunda metade do século XIX e na primeira metade do século XX, esse conceito se fortaleceu na área, inclusive pelo 
fato de que muitas publicações, em relação às pessoas com deficiências, eram oriundas de textos de docentes de clínica neurológica e psiquiátrica das faculdades de Medicina, avalizados por profissionais colaboradores de instituições especializadas. Nessa época, além do interesse e da intervenção da medicina na educação especial, entravam no país estudos estrangeiros, principalmente os franceses, apoiados em teorias como as de Alfred Binet e seus precursores nas medidas de inteligência.

\begin{abstract}
A Educação Especial se organizou tradicionalmente como atendimento educacional especializado substitutivo ao ensino comum, evidenciando diferentes compreensões, terminologias e modalidades que levaram à criação de instituições especializadas, escolas especiais e classes especiais. Essa organização, fundamentada no conceito de normalidade/anormalidade, determina formas de atendimento clínico-terapêutico fortemente ancorado nos testes psicométricos que, por meio de diagnósticos, definem as práticas escolares para os estudantes com deficiência (BRASIL, 2008, p. 1-2).
\end{abstract}

Mesmo com as discussões fomentadas em uma ótica de mudanças por meio de orientações da Educação em Direitos Humanos a partir de 1948 e posteriormente na legislação educacional brasileira recente, que tem uma proposta mais voltada às diferenças sobre a deficiência intelectual, constatam-se alguns atravessamentos, entre os quais a conceituação, o diagnóstico e a classificação da deficiência intelectual pela e na escola. Historicamente o diagnóstico tem sido realizado por meio de parecer médico, subsidiado por manuais diagnósticos e estatísticos, nos quais, com o passar do tempo, são incluídas novas definições de deficiência intelectual, que promovem mudanças nos diagnósticos.

Em relação ao tema, Caiado, Baptista e Jesus (2017), ao apresentarem os primeiros resultados de um estudo sobre os conceitos vigentes no Brasil, referentes à deficiência mental/intelectual, destacam, entre outros aspectos discutidos, as políticas públicas de educação especial em vigência nos Estados do Espírito Santo, Rio Grande do Sul e São Paulo. Cada um deles, apesar de seguirem os documentos oficiais, dispõe de suas próprias orientações, tanto em nível estadual quanto municipal. Os alunos, em relação à deficiência mental/intelectual, são vistos de maneiras diferentes, o que pressupõe formas de agir diversas.

Para esses autores, tal falta de unidade em torno do termo tem se constituído em um complicador nos processos de identificação dos alunos, bem como, nos processos de encaminhamento aos serviços disponibilizados nos sistemas públicos de ensino. Ao mesmo tempo, outra questão se sobrepõe à problematização levantada pelos autores: a caracterização vigente no Manual de Diagnóstico e Estatística de Transtornos Mentais (DSM-V) e no Código Internacional de Doenças (CID-10), com conceituação, diagnóstico e classificação em relação à deficiência intelectual, e na Classificação Internacional de Funcionalidade, Incapacidade e Saúde (CIF), que coloca os sujeitos dentro de um padrão. Então, ao mesmo tempo em que carecemos de entendimento em nível nacional para compreender a utilização do conceito de deficiência intelectual em nível escolar, estamos aprisionados a critérios construídos sócio-historicamente e ainda inacessíveis em termos de entendimento e discussão para a maioria dos profissionais que desenvolvem o trabalho pedagógico na escola. 
Os estudos mais recentes no campo da educação especial enfatizam que as definições e uso de classificações devem ser contextualizados, não se esgotando na mera especificação ou categorização atribuída a um quadro de deficiência, transtorno, distúrbio, síndrome ou aptidão. Considera-se que as pessoas se modificam continuamente, transformando o contexto no qual se inserem. Esse dinamismo exige uma atuação pedagógica voltada para alterar a situação de exclusão, reforçando a importância dos ambientes heterogêneos para a promoção da aprendizagem de todos os estudantes (BRASIL, 2008, p. 11).

Nesse ínterim, a educação especial, como modalidade de educação escolar, organiza a escolarização dos alunos público-alvo por ela atendidos que, de acordo com a Política Nacional de Educação Especial na Perspectiva da Educação Inclusiva (PNEEPEI), de 2008, são aqueles com deficiência, transtornos globais de desenvolvimento e com altas habilidades/superdotação. É importante destacar que recentemente houve uma mudança terminológica da expressão Transtornos Globais do Desenvolvimento (TGD) para Transtorno do Espectro Autista (TEA).

Nesses termos, é pertinente perguntar-nos: se levarmos em conta o QI como balizador para identificação desses sujeitos, de que modo serão vistos os alunos com deficiência intelectual em uma sociedade que cada vez mais valoriza a inteligência artificial? Nessa esteira, a literatura aponta que a escola e a sociedade reforçam o desvio, buscando aquilo que falta (AMARAL, 1998; CAETANO, 2009; MAFEZONI; COSTA; SILVA, 2012), tendo como base a dicotomia entre o quociente de inteligência e a deficiência intelectual. Não se trata aqui de realizar uma crítica infundada aos saberes da medicina e da psicologia, desconsiderando suas contribuições e deixando a área da educação especial isenta de suas responsabilidades, mas sim de compreender essa relação, bem como os arranjos históricos que apoiam os modos como a escola concebe e age pedagogicamente com esse público até os dias atuais, assim como esse tema não deve ser visto como dado histórico que permaneceu no passado, mas que está presente nas práticas pedagógicas atuais.

\section{O CONCEITO DE DEFICIÊNCIA INTELECTUAL E A ESCOLA}

O uso do conceito de deficiência intelectual na escola, destituído de outras ações pedagógicas, além de arrancar a subjetividade do indivíduo, não indica quais são os motivos do déficit de um aluno, nem tampouco mostra o que e como fazer. Entre outras, uma questão inter-relacionada com a problemática é a dicotomia na utilização do conceito vigente que tem por princípio a diferenciação dos indivíduos, seleciona e preserva um ambiente educacional determinado, pressionando-os a se ajustarem a um modelo que tem força e se mantém na escola negando os princípios da inclusão escolar.

Nesse sentido, os dados coletados e as discussões realizadas por Caetano $(2002,2009)$ e Mafezoni, Costa e Silva (2012) têm apontado uma imprecisão acerca do conceito de deficiência intelectual por professores em formação inicial e continuada, evidenciando diferentes categorias a respeito desse conceito e da pessoa com deficiência intelectual. Nessa perspectiva, se faz importante evidenciar os estudos que contribuem para o entendimento dessa temática, como o de Schütz (2006), que, por meio de entrevistas realizadas com 
três professoras atuantes nos anos iniciais do ensino fundamental de uma escola pública localizada no município de Itajaí/SC, analisa suas concepções de deficiência mental e de aprendizagem, entre outros aspectos.

Sobre a concepção de deficiência mental, a pesquisadora constata que o fator orgânico e biológico sobressai, isentando os fatores externos à criança, e que as concepções compartilhadas pelas docentes foram as seguintes: "Deficiência mental é uma falta, ausência ou deficiência de inteligência"; "É um certo problema no cérebro que o impossibilita de acompanhar a sua idade real"; "Insuficiência, carência, falta de algo para reestruturar a mente, não agindo de acordo com os padrões normais da sociedade" (SCHÜTZ, 2006, p. 43). A autora discute que "[...] por mais que o conceito de deficiência mental venha sendo discutido a partir de determinantes políticos, econômicos e sociais, os quais secundarizam a deficiência, esta continua a ser entendida sob o ponto de vista da medicalização" (SCHÜTZ, 2006, p. 43).

O predomínio da perspectiva organicista limita o problema do fracasso escolar ao plano individual, o que acarreta na responsabilização da criança pelos problemas de aprendizagem, isentando-se as dimensões política e pedagógica que influenciam a realidade escolar. Em torno dessa discussão, Mafezoni e Simon (2020) estudaram as concepções de professores de educação especial sobre a pessoa com deficiência intelectual em um município da Região Metropolitana da Grande Vitória/ES, onde uma das constatações é de que ela ainda é concebida em uma perspectiva de limitação de ordem biológica em relação às possibilidades de desenvolvimento e aprendizagem. Nesse sentido, pontuam que essas concepções estigmatizantes contribuem para a construção de uma postura pedagógica que compreende a pessoa com deficiência intelectual como um indivíduo delimitado pela não aprendizagem, sobre o qual há pouca ou não há expectativa.

Nessa esteira, De Vitta, De Vitta e Monteiro (2010) analisam a percepção de professores de educação infantil sobre a educação de crianças com deficiência na faixa etária de 3 a 6 anos. Realizaram entrevistas com doze professores de educação infantil, divididos em três grupos: de escolas especiais, de escolas comuns que trabalham com crianças com deficiência inseridas em suas classes e de escolas comuns que não possuem em suas classes crianças com deficiências (DE VITTA; DE VITTA; MONTEIRO, 2010, p. 417).

Alguns docentes demonstraram ter dificuldade para definir o termo deficiência, quando afirmaram que "[...] todas as pessoas em alguma medida possuem características diferentes que dificultam certas atividades". O conceito de deficiência mental, dado pela maioria dos professores, é entendido como uma "[...] dificuldade de aprendizagem, de compreensão [...]", relacionada à ideia de "[...] incapacidade, diferença e anomalia". Percebe-se que, na definição de deficiência mental, os docentes entendem que o problema se encontra na criança, é parte dela, tornando-se difícil modificar o quadro apresentado (DE VITTA; DE VITTA; MONTEIRO, 2010, p. 419). Concordamos com as considerações de Caiado, Baptista e Jesus (2017), em relação à falta de definição nos documentos nacionais em torno do termo "deficiência intelectual", ao passo que isso tem se constituído como um complicador nos processos de identificação dos alunos, bem como, nos de encaminhamento aos serviços disponibilizados nos sistemas públicos de ensino.

Da mesma maneira, Raymundo (2010) objetivou compreender como acontece o processo de aprendizagem da criança com deficiência intelectual na educação infantil. De 
modo a entender as concepções compartilhadas por professores acerca da deficiência intelectual, Raymundo entrevistou dez profissionais de um Centro Municipal de Educação Infantil (CMEI), entre os quais duas professoras, duas pedagogas, um professor de Educação Física, uma professora de Artes, uma professora do Berçário, uma professora do Jardim, e duas estagiárias (RAYMUNDO, 2010, p. 139). Destaca ter observado que os profissionais da educação entrevistados (professores, pedagogos e estagiários) transitam entre a não compreensão do conceito de deficiência intelectual e a sua associação à mera dificuldade de aprendizagem. Já os professores de Educação Física e de Artes, mesmo trabalhando em um ambiente escolar e lidando diariamente com alunos com deficiência intelectual, isentam-se da responsabilidade de conhecer sobre a educação especial por atribuírem essa função apenas aos professores licenciados em Pedagogia. Estudos também têm apontado (CAETANO, 2002; COSTA; SILVA, 2012; ESTEVAM, 2019) que, muitas vezes, os professores de sala de aula comum entendem que o aluno da modalidade educação especial e seu processo de escolarização são de responsabilidade dos professores especializados.

Adicionalmente, Teles (2010) buscou compreender os processos de construção de significados pelo professor sobre a inclusão e a escolarização de alunos com deficiência intelectual no ensino fundamental. Para a elaboração de seus dados, Teles realizou entrevistas semiestruturadas com três professoras de salas inclusivas dos primeiros anos do ensino fundamental que trabalham com alunos incluídos com deficiência intelectual. Entre as questões apresentadas às professoras, indaga-se a respeito da compreensão sobre o significado de deficiência (TELES, 2010, p. 35). Teles explica que, pelo fato de a primeira professora entrevistada (denominada P1) estar realizando um curso de formação continuada sobre Educação Inclusiva, promovido pela Secretaria de Educação do Distrito Federal, sua compreensão sobre deficiência encontra-se em um processo de ressignificação, revelando uma abordagem mais crítica acerca do conceito de deficiência intelectual, principalmente se comparado às definições dadas pelos educadores das pesquisas já analisadas. A segunda e a terceira professoras entrevistadas entendem a deficiência intelectual como um limite cognitivo, capaz de gerar dificuldade de aprendizagem (TELES, 2010, p. 109). No estudo de Mafezoni e Simon (2020) já citado, também foi observado o surgimento de uma tendência que busca superar essa perspectiva patologizante em direção a uma concepção que aposta nas potencialidades da pessoa com deficiência intelectual.

Rossato e Leonardo (2011) objetivaram compreender a educação escolar oferecida aos alunos com deficiência intelectual, de maneira a conhecer as expectativas de aprendizagem e a concepção dos educadores acerca da deficiência intelectual, imbrincadas no ensino com tais alunos. Para tanto, foram realizadas entrevistas com 21 educadores pertencentes a três escolas especiais - Associações de Pais e Amigos dos Excepcionais (APAE) -, localizadas no Estado do Paraná (ROSSATO; LEONARDO, 2011, p. 71). Analisando os resultados obtidos, ficou claro para as pesquisadoras que a maioria dos docentes concebe a deficiência intelectual como algo "estático, irreversível, instalado, sem possibilidade de desenvolvimento", fato que evidencia a "[...] falta de perspectiva de desenvolvimento em relação às pessoas com deficiência intelectual, estando suas possibilidades de aprendizado cingidas ao aspecto orgânico". Percebe-se que os docentes entrevistados relacionam a deficiência intelectual a uma condição estável e irreversível, a qual limita o exercício das 
funções cognitivas do indivíduo, de quem se deve esperar (e celebrar como uma conquista) o menor desenvolvimento possível (ROSSATO; LEONARDO, 2011, p. 80-81).

Valentim e Oliveira (2013) buscaram identificar as concepções de um grupo de professores do ensino fundamental sobre deficiência intelectual e avaliação da aprendizagem escolar. A metodologia adotada revelou-se similar às anteriores, contando com a realização de entrevistas semiestruturadas com seis professores que lecionavam para alunos com deficiência intelectual matriculados nos últimos anos do ensino fundamental I (VALENTIM; OLIVEIRA, 2013, p. 854). As autoras dispõem que os conceitos manifestados pelos professores acerca da deficiência intelectual se referem, com mais frequência, a uma concepção individual: "[..] a dificuldade ou incapacidade está localizada apenas no sujeito e foi relacionada ao comprometimento cognitivo, de raciocínio, atraso em relação à idade cronológica e dificuldade para aprender" (VALENTIM; OLIVEIRA, 2013, p. 855).

Apresentamos as contribuições de Camizão (2016), que teve como principal objetivo analisar conhecimentos, concepções e práticas de professores de educação especial que atuam no atendimento educacional especializado na educação infantil, direcionados à criança com deficiência intelectual, em relação à vigência do modelo médico-psicológico. Os dados foram obtidos por meio da realização de entrevistas semiestruturadas a dez professores de educação infantil de quatro regiões do município de Vitória/ES (CAMIZÃO, 2016, p. 10).

A análise do conjunto de respostas dadas pelos participantes demonstrou que metade dos professores entrevistados entende a deficiência intelectual como uma limitação da criança. No entanto, Camizão chama a atenção para respostas que rompem com essa tendência, revelando uma faceta menos organicista e mais social acerca da deficiência intelectual, “[...] que não impõe ao outro uma limitação, mas que sob outra perspectiva compreende o sujeito como um ser social que, independentemente de suas características biológicas, expressa-se e vive de uma forma própria" (CAMIZ̃̃O, 2016, p. 128).

A partir de uma leitura enviesada que, de um modo geral, pode se realizar na escola sobre a deficiência intelectual, o aluno tende a se tornar o que desejam que ele seja. Dessa forma, fabricamos e endereçamos os rótulos àqueles que elegemos e, inferimos que esse possa ser um dos motivos pelo qual o trabalho pedagógico com alunos com deficiência mental/ intelectual tem se apresentado como um desafio, principalmente para os professores atuantes em sala de aula regular e no Atendimento Educacional Especializado (AEE). Assim, é preciso estar atento ao fato de que o conceito de deficiência intelectual é insólito, à medida que ele se constituiu de maneira abstrata e multifacetada na escola, por meio da intervenção de uma Educação Especial baseada em um olhar clínico-psicológico-pedagógico.

\section{Algumas definições da AADID SOBRe A DEFICIÊNCIA INTELECTUAL}

Conforme o momento sociopolítico-econômico, o conceito de deficiência intelectual se moldou e tomou novos contornos, como no caso das reformulações realizadas pela AADID. É imperativo pensarmos no entendimento dos professores em relação à deficiência intelectual, considerando que podem levar resquícios das definições da atual AADID sobre 
a deficiência intelectual em seu imaginário social, na medida em que, ao longo do tempo, a escola acolheu o modo médico-psicológico de olhar a deficiência intelectual, inserindo-o em suas práticas pedagógicas, por meio de escolas e classes especiais. Nesse sentido, apresentaremos alguns aspectos das definições construídas:

[...] A primeira definição foi apresentada por Tredgold em 1908 e estabelecia
que "deficiência mental era um estado de defeito mental a partir do nascimento
ou idade mais precoce em função do desenvolvimento cerebral incompleto, e
em consequência disso, a pessoa afetada se tornava incapaz de desempenhar
suas tarefas como membro da sociedade". Essa definição enfatizava a incura-
bilidade e se referia a um status permanente de retardo mental (ALMEIDA,
2004, p. 34).

A autora esclarece que essa definição se baseava na perspectiva médica, a partir do diagnóstico clínico estabelecido, apontando que as crianças diagnosticadas com deficiência mental eram vistas sem chances de cura ou melhoria, portanto não sendo estimuladas a aprender e sendo estigmatizadas como incapazes de participar da vida em sociedade. Com o passar dos anos, o conceito de deficiência mental foi modificado, porém permaneceu a ideia de que a pessoa com deficiência mental era um sujeito que não mantinha relações sociais devido à incapacidade de adaptar-se aos diversos ambientes, os quais apenas pessoas que não possuíam deficiência eram capazes de frequentar.

Em 1937, Tredgold apresentou uma nova definição para deficiência mental, conservando o caráter biológico da deficiência, ao defini-la como "[...] estado de desenvolvimento mental incompleto, de tal tipo e grau que tornava o indivíduo incapaz de se adaptar ao ambiente normal de forma a manter uma existência independente supervisão, controle e suporte externo" (TREDGOLD apud ALMEIDA, 2004, p. 34). Vemos que, nas duas definições, a deficiência mental é considerada como um desenvolvimento mental incompleto e de cunho individual, que desconsidera as questões sociais e culturais da pessoa, dando ênfase na incurabilidade.

Em 1941, Doll apresentou uma nova definição de deficiência mental como sendo estado de incompetência social obtido na maturidade e resultante de um desenvolvimento aprisionado na origem constitucional (hereditário ou adquirido), sendo essa condição essencialmente incurável por meio de tratamento e irremediável por meio de treinamento [...] (ALMEIDA, 2004, p. 34). A autora argumenta que a afirmação de que a deficiência mental é incurável também indica um ponto em comum nas definições. Um novo ponto levantado foi o da hereditariedade e a possibilidade de apresentar a deficiência em outros momentos da vida, haja vista que as definições já mencionadas apontam para causas intrauterinas ou nos primeiros anos de vida, mas não expõe a possibilidade da hereditariedade.

Segundo Almeida (2004, p. 34), Herber apresentou a seguinte definição em 1959: “[...] Retardo mental se refere a um funcionamento intelectual geral abaixo da média, que se origina no período de desenvolvimento e que está associado a deficiências em uma ou mais das seguintes condições: maturação, aprendizagem e ajustamento social [...]". A autora pontua que eram discutidos termos e conceitos concernentes à deficiência/ao retardo 
mental, com a introdução de questões do funcionamento do intelecto ${ }^{2}$ e a avaliação de comportamentos e níveis de desenvolvimento das pessoas com deficiência.

Almeida (2004) menciona que, em 1961, Rick Herber, presidente da AAMR na época, estabeleceu o novo conceito de retardo mental, que se referia ao funcionamento intelectual abaixo da média que se origina durante o período do desenvolvimento e está associado a deficiências no comportamento adaptativo. De acordo com a autora, algumas críticas foram apontadas ao modo como eram feitos os procedimentos de avaliação do comportamento adaptativo, ${ }^{3}$ por meio de testes de inteligência ${ }^{4}$ que, para estudiosos da época, não eram suficientes para definir diagnósticos concretos, de modo que esses testes, além de não serem capazes de identificar níveis de desenvolvimento em longo prazo, ainda poderiam caracterizar crianças de diferentes culturas como deficientes mentais.

Tendo em vista a base clínica para a definição e o diagnóstico da deficiência intelectual, a sua avalição ocorria por meio de testes de inteligência. Nesse sentido, é importante refletir que, dependendo dos objetivos e da forma de utilização, os testes de inteligência podem ter um caráter discriminatório, na medida em que há a afirmação de que uma pessoa possui uma inteligência abaixo da média ou superior à média, com base em um referencial para essa classificação. Para Moysés e Collares (1997, p. 63), os testes de inteligência são instrumentos que visam, essencialmente, à classificação das pessoas, filiados ao ideário eugenista.

As autoras argumentam que os procedimentos feitos pelos testes de inteligência se limitavam apenas à situação em que a pessoa se apresentava no momento da realização do teste, desconsiderando que cada indivíduo se desenvolve conforme o tempo e o meio social, ou seja, quando é aplicado o teste de Quociente de Inteligência (QI) em um indivíduo busca-se compreender os níveis de sentidos em relação ao raciocínio lógico, o meio simbólico e a percepção dessa pessoa apenas no momento em que é realizado. No entanto, também é necessário considerar-se o desenvolvimento promovido por intermédio do contato dessa pessoa com o meio social no decorrer do tempo.

Concordamos com as autoras quando opinam que se limitar apenas ao presente é uma forma equivocada e que padroniza as pessoas, já que para diagnosticar o "nível de inteligência" de um sujeito não se deve restringir a testes padronizados, pois esse método precisa ser discutido de forma mais abrangente, considerando-se as diferentes culturas e o processo de desenvolvimento individual. Além disso, é importante refletirmos sobre o modelo usado para as definições acerca da deficiência intelectual da AADID, uma vez que os padrões culturais e sociais norte-americanos são diferentes da cultura da sociedade brasileira. Dessa forma, é preciso estarmos atentos à utilização de conceitos-padrão, tendo em vista as diferentes relações sociopolítico-econômicas existente nesses países.

2 O funcionamento do intelecto, também conhecido como inteligência, se refere à capacidade mental geral de um indivíduo, considerando aspectos como aprendizado, raciocínio, resolução de problemas, entre outros.

3 Comportamento adaptativo: trata-se de conjuntos de habilidades conceituais, sociais e práticas que são aprendidas e desempenhadas pelas pessoas em suas vidas cotidianas; os testes padronizados são uma forma de determinar as limitações do comportamento adaptativo.

4 Testes de inteligência: trata-se de testes desenvolvidos para avaliar a capacidade cognitiva de um sujeito; uma maneira de medir o funcionamento intelectual é por meio do Quociente de Inteligência (QI), abordando o valor que é calculado por meio dos testes de inteligência; geralmente, uma pontuação no teste de QI em torno de 70 ou até 75 indica uma limitação no funcionamento intelectual. 
A AAMR reorganizou seu manual, em 1973, e Grossman assumiu a frente desse trabalho. A deficiência mental foi definida como "[...] funcionamento intelectual significativo abaixo da média, originado no período de desenvolvimento contendo déficits no comportamento adaptativo e manifestada no período de desenvolvimento" (ALMEIDA, 2004, p. 35). O período de desenvolvimento foi estendido para os 18 anos de idade, tendo em vista o período de início e término dos estudos. Nesse manual, o comportamento adaptativo foi caracterizado em graus de eficiência, ou seja, as pessoas alcançariam padrões de independência pessoal e responsabilidade social, esperados para a sua idade e grupo social. Essa verificação era realizada por meio da aplicação de testes de inteligência, havendo a possibilidade de identificar o nível de desenvolvimento da criança com deficiência mental. Segundo Almeida (2004), o manual de 1973 foi reformulado em 1977 e a definição de deficiência mental continuou a mesma, porém a nova versão deixou explícita a perspectiva médica, assegurando que apenas os profissionais da área da saúde, devidamente capacitados, poderiam assegurar que uma criança possuía deficiência mental.

Uma nova revisão do conceito de deficiência mental foi estabelecida, em 1983, e mencionava o funcionamento intelectual geral significativamente abaixo da média, associado a deficiências no comportamento adaptativo, manifestadas no período de desenvolvimento. Para Almeida (2004), a perspectiva clínica ainda estava explícita nessa edição, a qual trazia uma definição preestabelecida e engessada, omitindo as desigualdades e/ou diferenças culturais, às quais muitas pessoas estariam sujeitas. Nesse sentido, houve um aumento significativo no número de diagnósticos de crianças com deficiência mental, as quais apresentavam um contexto socioeconômico diferenciado, causando sua exclusão em diversos meios sociais. Collares e Moysés (1994) questionam o diagnóstico médico, na medida em que um aluno é patenteado com um laudo a fim de justificar o motivo de não estar aprendendo, validando dessa maneira para a escola o fracasso escolar. A questão médico-patológica tem estado vigente em relação ao baixo desempenho da criança na escola cada vez mais e os profissionais da educação, tomando esse diagnóstico como imutável, podem continuar numa zona de conforto, desconsiderando as potencialidades dos educandos.

Em 1992, outros fatores foram considerados para uma nova reformulação do conceito de deficiência mental, agora sendo liderado por Luckasson. De acordo com Almeida (2004), no manual de 1992, a AAMR tinha como objetivo problematizar a necessidade de não analisar a deficiência como um traço absoluto do sujeito, e sim como fruto de uma interação do funcionamento intelectual e seu ambiente. Nesse sentido, buscou-se o avanço teórico no conceito de comportamento adaptativo, apontado também como "o sistema de apoio" que as pessoas com deficiência mental necessitam. Em 1992, a deficiência mental foi definida como retardo mental que:

[...] se refere a limitações substanciais no funcionamento atual dos indivíduos, sendo caracterizado por um funcionamento intelectual significativamente abaixo da média, existindo concomitante com relativa limitação associada a duas ou mais áreas de condutas adaptativas, indicadas a seguir: comunicação, autocuidado, vida no lar, habilidades sociais, desempenho na comunidade, independência na locomoção, saúde e segurança, habilidades acadêmicas funcionais, lazer e trabalho. O retardo mental se manifesta antes dos 18 anos (LUCKASSON et al., 1992 apud ALMEIDA, 2004, p. 37). 
Almeida (2004) explica que, com a modificação do conceito, passou-se também a considerar a necessidade de apoio, de acordo com o nível de deficiência mental, caracterizado como leve, moderado, severo e profundo; dessa forma, os quatro níveis de apoio para o desenvolvimento do indivíduo foram classificados como intermitente, ilimitado, amplo e permanente. O manual da AAMR de 1992 seguiu a adoção do sistema de níveis de suporte $^{5}$ a fim de descrever qual nível era propício para o sujeito com deficiência mental, de acordo com o comportamento adaptativo de cada indivíduo, no intuito de que ele pudesse desenvolver-se.

Segundo Januzzi (2006), o termo "deficiente mental" foi utilizado no Congresso de Genebra, como uma tentativa de padronizar a forma de se referir às pessoas e, ao mesmo tempo, substituir o termo "anormal". Anteriormente não havia distinção entre as limitações de ordem sensorial, física ou intelectual, pois todos eram caracterizados como desvios de normalidade. Em 2002, uma nova definição de deficiência mental foi apresentada pela Associação Americana, com algumas mudanças e discussões significativas sobre as antigas edições exibidas. De acordo com Carvalho e Maciel (2002, p. 150), o Sistema 2002 consistia numa concepção multidimensional, funcional e bioecológica de deficiência mental, agregando sucessivas inovações e reflexões teóricas e empíricas em relação aos modelos anteriores. Dessa maneira, o novo conceito de deficiência mental era caracterizado naquele momento como deficiência acompanhada de limitações comportamentais e intelectuais, evidentes nas habilidades pessoais, sociais e conceituais, identificada até os 18 anos de idade. Esse novo conceito trazia para o processo do diagnóstico a necessidade de observação de alguns critérios como funcionamento intelectual, comportamento adaptativo e idade de início das adaptações ou dos sinais indicativos de atraso no desenvolvimento.

Carvalho e Maciel (2002) mencionam que o sistema de 2002 apresentava uma relação existente entre o funcionamento intelectual do indivíduo e os apoios exigidos, ou seja, de acordo com o grau de eficiência caracterizado, eram determinadas as condições de apoio para o sujeito, classificado como intermitente, ilimitado, amplo e permanente, e as cinco dimensões que envolvem aspectos relacionados às pessoas, sendo elas as habilidades intelectuais em que são identificadas na capacidade de aprendizado do indivíduo e avaliadas por meio de testes, tendo como foco a questão da inteligência.

No entanto, o comportamento adaptativo tem ligação com as habilidades práticas, sociais e conceituais que as pessoas desenvolvem para dar sentido ao cotidiano em seu redor; com as participações, as interações e os papéis sociais que medeiam a qualidade na participação do indivíduo nos ambientes sociais; com a saúde, em que são considerados aspectos como saúde física e mental, com os efeitos de medicação e avaliações das necessidades de apoio necessário para o bem-estar do indivíduo; com os contextos, que indicam a relação do indivíduo com os vários ambientes vivenciados por ele. Por meio disso, compreendemos que, mesmo com o passar do tempo, ainda é notório que as relações que envolvem o funcionamento intelectual do indivíduo baseiam-se em critérios médicos, que padronizam as pessoas.

5 Utilizado para descrever os níveis de deficiência mental: leve, moderado, severo e profundo. Por meio desse método, é possível estabelecer qual é o apoio necessário para o indivíduo. Esses apoios são classificados como intermitentes, limitados, contínuos ou pervasivos. 
Apesar de todas as reformulações nas definições do conceito de deficiência mental, ainda existia um ponto em discussão: os constrangimentos e a indiferença sofridos pelas pessoas que viviam nessa condição e pelos seus familiares. Sassaki (2008) afirma que as pessoas com deficiência intelectual eram concebidas pejorativamente como retardadas ou mongoloides, classificadas por níveis de QI, e que muitas vezes tinham resultados abaixo do nível esperado para a idade, sendo consideradas sem inteligência.

De acordo com o autor, a alteração da nomenclatura de deficiência mental para deficiência intelectual ocorreu devido a estudos e discussões que defendiam que o déficit cognitivo não estava na mente como um todo, mas apenas no intelecto. A partir dessa perspectiva, foram realizados debates que resultaram em uma votação que alterou o nome Associação Americana de Retardamento Mental (AAMR) para Associação Americana de Deficiência Intelectual e Desenvolvimento (AADID), a partir de janeiro de 2007.

\footnotetext{
O nome da AAIDD tem sido uma contínua fonte de discussão na comunidade que lida com deficiências. Embora o termo "deficiência mental" (DM) seja amplamente percebido como uma condição que existe, foi também reconhecido que o termo é propenso ao abuso, à interpretação errônea, e foi convertido em um insulto, especialmente para pessoas com deficiência e seus familiares. Além disso, o nome AAMR era percebido que não estava em sintonia com a progressista orientação de informações, produtos e serviços oferecidos pela Associação (SASSAKI, 2008).
}

No ano de 2010, a AADID apresentou uma nova definição para o conceito de deficiência intelectual, sendo caracterizada por "limitações significativas tanto no funcionamento intelectual quanto no comportamento adaptativo, que abrange muitas habilidades sociais e práticas cotidianas. Essa deficiência tem origem antes dos 18 anos de idade. A nova definição mostrou-se, mais uma vez, em um viés excludente, caracterizado pelo nível baixo do QI, ou seja, pela taxa do quociente abaixo do nível esperado para a idade da pessoa, o que causa limitações adaptativas nas áreas de habilidades, que podem ser identificadas desde os primeiros anos de vida até os 18 anos de idade, com dificuldades no aprendizado e na realização de atividades comuns às pessoas que não possuem deficiência intelectual. É válido ressaltar que o conceito de deficiência intelectual alcançou mudanças no decorrer do tempo, mas é importante não perder de vista que o olhar dos professores, demais profissionais e da sociedade também sejam alterados, com uma visão mais humanizada em relação ao indivíduo com deficiência intelectual.

\section{CONSIDERAÇões FINAIS}

A AADID passou por processos de atualização em suas edições, tanto de conceitos e nomenclatura como de novos entendimentos sobre a deficiência com o aumento dos estudos nesse campo, havendo a necessidade de alteração também nos documentos.

Essa forma de conceber pessoas tem trazido prejuízos para as possibilidades de aprendizagem e desenvolvimento desses sujeitos na escola e, por conseguinte, na sua vida na sociedade. De acordo com Sanches-Ferreira, Santos e Santos (2012), o pressuposto de in- 
teligência como algo intrínseco e estático surge a partir de uma premissa de construção da deficiência intelectual sob o viés do funcionamento intelectual abaixo da média. Nessa versão, constitui-se o QI, nascido há mais de dois séculos, subsidiando diagnósticos e prognósticos devastadores que avaliam os alunos com deficiências, lhes oferecendo poucas chances de desenvolvimento de suas potencialidades na escola e na sociedade. Na atualidade, de um lado, acreditamos que o olhar dos professores para a deficiência intelectual ainda necessita ser ressignificado; de outro lado, esse movimento tem acontecido por meio de colaboração entre a universidade e os sistemas em rede de ensino, por meio de projetos de pesquisa/ extensão e de formação continuada de professores generalistas e especialistas, assim como de gestores de educação especial, como mostram os estudos de Almeida (2016), Almeida e Zambon (2016) e Estevam (2019).

Nesse sentido, tendo em vista as mudanças na classificação e na definição da deficiência intelectual, compreendemos que ainda há um longo caminho a ser percorrido, a fim de superar as barreiras encontradas na sociedade, que ainda carrega preconceitos sobre a deficiência. É válido ressaltar que o conceito de deficiência intelectual tem sofrido modificações, o que pode auxiliar no olhar e na compreensão social acerca do fenômeno da deficiência intelectual e da pessoa que vive essa condição, com uma visão mais humanizada em relação ao indivíduo.

O entendimento de que vivemos em uma sociedade heterogênea é a forma mais humana de perceber que diferenças existem e que a pessoa com deficiência intelectual é um cidadão com direitos, um ser histórico-social que deve se apropriar dos bens culturais construídos pela humanidade. Em relação à inclusão escolar de alunos com deficiência intelectual, não bastam apenas mudanças na nomenclatura, mas também é preciso considerar que o uso de termos e conceitos está imbuído de ideologias. Tal utilização deve ser visualizada e discutida na escola, considerando as diferenças entre as culturas, as linguagens e as potencialidades.

\section{REFERÊNCIAS}

ALMEIDA, M. A. Apresentação e análise das definições de deficiência mental propostas pela AAMR - Associação Americana de Retardo Mental de 1908 a 2002. Revista de Educação, Campinas, n. 16, p. 33-48, jun. 2004. Disponível em: http://periodicos.puc-campinas.edu.br/seer/index.php/\%20reveduca\%20cao/article/viewFile/284/267. Acesso em: 21 out. 2018.

ALMEIDA, M. L. Desafios e Possibilidades na Formação Continuada de Profissionais da Educação: trajetória de um grupo de estudo-reflexão. In: MENDES, E. G.; ALMEIDA, M. A. (Org.). Inclusão Escolar e Educação Especial no Brasil: entre o instituído e o instituinte, 1. ed. Marílidea: ABPEE, 2016, v. 1, p. 169-190.

ALMEIDA, M. L. de.; ZAMBON, G. F. de O. Gestão em educação especial e formação continuada de profissionais da educação na perspectiva da inclusão escolar. In: VICTOR, S. L.; OLIVEIRA, I. M. Educação Especial: políticas e formação. São Carlos: ABPEE, 2016. 
AMARAL, L. A. Sobre crocodilos e avestruzes: falando de diferenças físicas, preconceitos e sua superação. In: AQUINO, J. G. (Org.). Diferenças e preconceito na escola: alternativas teóricas e práticas, 2. ed. São Paulo: Summus, 1998, p. 11-30.

ANDRADE, M. M. Introdução a metodologia do trabalho científico, 10. ed. São Paulo: Atlas, 2010.

BATISTA, C. A. M. Inclusão escolar: equívocos e insistência. Uma história de reis, príncipes, monstros, castelos, cachorros, leões, meninos e meninas, 2009, 283s. Tese (Doutorado em Ciências Sociais) - Pontifícia Universidade Católica de São Paulo, São Paulo, 2009.

BRASIL. Lei no . 13.146, de 6 de julho de 2015. Institui a Lei Brasileira de Inclusão da Pessoa com Deficiência (Estatuto da Pessoa com Deficiência). Diário Oficial [da] República Federativa do Brasil, Brasília, 6 jul. 2015. Disponível em: http://www.planalto.gov.br/ ccivil_03/_ato2015-2018/2015/lei/113146.htm. Acesso em: 15 set. 2018.

BRASIL. Ministério da Educação. Política Nacional de Educação Especial na Perspectiva da Educação Inclusiva. Documento elaborado pelo Grupo de Trabalho nomeado pela Portaria ${ }^{\circ}$. 555/2007, prorrogada pela Portaria $n^{\circ}$. 948/2007, entregue ao Ministro da Educação em 7 de janeiro de 2008. Disponível em: http://portal.mec.gov.br/arquivos/pdf/ politicaeducespecial.pdf. Acesso em: 21 out. 2018.

BRIDI, F. R. S. Processos de identificação e diagnóstico: os alunos com deficiência mental no contexto do atendimento educacional especializado, 2011, 210s. Tese (Doutorado em Educação) - Programa de Pós-Graduação em Educação, Universidade Federal do Rio Grande do Sul, Porto Alegre, 2011.

BUENO. J. G. S. A produção social da identidade do anormal. In: FREITAS, M. C. de (Org.). História social da infância no Brasil, 7. ed. São Paulo: Cortez, 2009.

CAETANO, A. M. A formação inicial de professores na perspectiva da inclusão escolar de alunos com deficiência: o curso de Pedagogia da Universidade Federal do Espírito Santo, 2009, 238s. Tese (Doutorado em Educação) - Programa de Pós-Graduação em Educação, Universidade Federal do Espírito Santo, Vitória, 2009.

CAETANO, A. M. O processo de escolarização de alunos com deficiência mental incluídos nas séries finais do ensino fundamental, 2002, 73s. Dissertação (Mestrado em Educação) - Programa de Pós-Graduação em Educação, Universidade Federal do Espírito Santo, Vitória, 2002.

CAIADO, K. R. M.; BAPTISTA, C. R.; JESUS, D. M., Deficiência mental e deficiência intelectual em debate: primeiros apontamentos. In: CAIADO, K. R. M.; BAPTISTA, C. R.; JESUS; D. M. (Org.). Deficiência mental e deficiência intelectual em debate. Uberlândia: Navegando Publicações, 2017. 
CAMIZÃO, A. C. Conhecimentos, concepções e prática de professores de educação especial: o modelo médico-psicológico ainda vigora? 2016, 180s. Dissertação (Mestrado em Educação) - Programa de Pós-Graduação em Educação, Universidade Federal do Espírito Santo, Vitória, 2016.

CARVALHO, E. N. S. de; MACIEL, D. M. M. A. Nova concepção de deficiência mental segundo a American Association on Mental Retardation - AAMR: Sistema 2002. Temas psicol. [on-line], v. 11, n. 2, p. 147-156, 2003. Disponível em: http://pepsic.bvsalud.org/ pdf/tp/v11n2/v11n2a08.pdf. Acesso em: 21 out. 2018.

COLLARES, C. A. L.; MOYSÉS, M. A. A. A transformação do espaço pedagógico em espaço clínico (a patologização da educação). Publicação Série Ideias, São Paulo, n. 23, p. 25-31, 1994. Disponível em: http://evoluireducacional.com.br/wp-content/uploads/2012/08/A-Transforma $\%$ C3\%A7\%C3\%A3o-do-Espa $\%$ C3\%A7o-Pedag\%C3\%B3gico-em-Espa\%C3\%A7o-C1\%C3\%ADnico-A1.pdf. Acesso em: 21 out. 2018.

DE VITTA, F. C. F.; DE VITTA, A.; MONTEIRO, A. S. R. Percepção de professores de educação infantil sobre a inclusão da criança com deficiência. Revista Brasileira de Educação Especial, Marília, v. 16, n. 3, p. 415-428, dez. 2010.

DIAS, M. C. Construções discursivas acerca da deficiência intelectual: entre concepções e implicações para as políticas públicas, 2017, 345s. Tese (Doutorado) - Faculdade de Educação, Universidade de São Paulo, São Paulo, 2017.

ESTEVAM, Mariana Karoline Dias Coelho. Atuação do pedagogo na perspectiva da inclusão escolar: a articulação entre o professor do atendimento educacional especializado e o da sala de aula comum, 2019, 141s: Dissertação (Mestrado em Educação) - Programa de Pós-Graduação em Educação, Universidade Federal do Espírito Santo, Vitória, 2019.

GUARIDO, R. L. "O que não tem remédio, remediado está": medicalização da vida e algumas implicações da presença do saber médico na educação, 2008, 116s. Dissertação (Mestrado em Educação) - Universidade de São Paulo, São Paulo, 2008.

JANUZZI, G. S. de M. A educação do deficiente no Brasil: dos primórdios ao início do século XXI, 2. ed. Campinas: Autores Associados, 2006.

LIMA, T. C. S.; MIOTO, R. C. T. Procedimentos metodológicos na construção do conhecimento científico: a pesquisa bibliográfica. Rev. Katálysis, Florianópolis, v. 10, n. esp., p. 37-45, 2007.

MAFEZONI, A. C.; COSTA, C. R. R.; SILVA, F. N. G. As representações sociais de licenciandos sobre a deficiência em tempos de inclusão escolar. In: V CONGRESSO BRASILEIRO DE EDUCAÇÃO ESPECIAL, 5.; ENCONTRO NACIONAL DE PESQUISADO- 
RES EM EDUCAÇÃO ESPECIAL, 7, 2012, São Carlos. Anais [...]. São Carlos: UFSCar, 2012, v. 5.

MAFEZONI, A. C.; SIMON, C. A pessoa com deficiência intelectual e as concepções de professores de educação especial. Revista Educação em Perspectiva, Viçosa, v. 11, n. 40, p. 1-14, jul. 2020.

MOYSÉS, M. A. A.; COLLARES, C. A. L. Inteligência abstraída, crianças silenciadas: as avaliações de inteligência. Psicol. USP, São Paulo, v. 8, n. 1, 1997. DOI: http://dx. doi.org/10.1590/S0103-65641997000100005. Disponível em: http://www.scielo.br/scielo. php?script=sci_arttext\&pid=S0103-65641997000100005. Acesso em: 21 out. 2018.

RAYMUNDO, D. N. Indícios da aprendizagem da criança com deficiência intelectual: contribuições da abordagem histórico-cultural e a formação de educadores de educação infantil, 2010, 208s. Dissertação (Mestrado em Educação) - Programa de Pós-Graduação em Educação, Universidade Federal do Espírito Santo, Vitória, 2010.

ROSSATO, S. P. M.; LEONARDO, N. S. T. A deficiência intelectual na concepção de educadores da educação especial: contribuições da psicologia histórico-cultural. Revista Brasileira de Educação Especial, Marília, v. 17, n. 1, p. 71-86, jan./abr. 2011.

SANCHES-FERREIRA, M.; SANTOS, P. L.; SANTOS, M. A. A desconstrução do conceito de Deficiência Mental e a construção do conceito de Incapacidade Intelectual: de uma perspectiva estática a uma perspectiva dinâmica da funcionalidade. Rev. Bras. Ed. Esp., Marília, v. 18, n. 4, p. 553-568, out./dez. 2012.

SASSAKI, R. K. Deficiência Intelectual e Inclusão. Texto disponibilizado em 3 nov. 2008. Disponível em: http://www.planetaeducacao.com.br/portal/artigo.asp?artigo=1320. Acesso em: 3 nov. 2017.

SCHÜTZ, M. R. Avaliação escolar como instrumento de mediação da aprendizagem na educação inclusiva: desafios no cotidiano escolar, 2006, 132s. Dissertação (Mestrado em Educação) - Universidade do Vale do Itajaí, Itajaí, 2006.

SILVA, C. M. da. Deficiência intelectual no Brasil: uma análise relativa a um conceito e aos processos de escolarização, 2016, 102s. Dissertação (Mestrado em Educação) - Programa de Pós-Graduação em Educação, Universidade Federal do Rio Grande do Sul, Porto Alegre, 2016.

TELES, S. M. O professor no processo de inclusão de alunos com deficiência intelectual: um estudo sobre os significados construídos no fazer pedagógico, 2010, 130s. Dissertação (Mestrado em Desenvolvimento Humano e Saúde) - Instituto de Psicologia, Universidade de Brasília, Brasília, 2010. 
VALENTIM, F. O. D.; OLIVEIRA, A. A. S. Avaliação da aprendizagem e deficiência intelectual na perspectiva de professores do ensino comum. Revista Diálogo Educacional, Curitiba, v. 13, n. 40, p. 851-871, set./dez. 2013.

\section{DADOS DAS AUTORAS}

\section{Andressa Caetano Mafezoni}

Pós-Doutorado pela Universidade Federal Rural do Rio de Janeiro. Rio de Janeiro/RJ-Brasil Professora do Programa de Pós-Graduação do Mestrado Profissional em Educação da Universidade Federal do Espírito Santo. Vitória/ES-Brasil. andressamafezoni@yahoo. com.br

\section{ThaYná Marins CéSAR}

Graduada em Pedagogia pela Universidade Federal do Espírito Santo/ES-Brasil . thaynacesar16@gmail.com

\section{Damaris Santos de Souza}

Graduada em Pedagogia pela Universidade Federal do Espírito Santo/ES-Brasil. damaris.s. santos@hotmail.com

Submetido em: 16-7-2019

Aceito em: 10-9-2020 